\title{
LA INCIDENCIA DE HOSTIGAMIENTO $Y$ CRÍMENES DE ODIO POR ORIENTACIÓN SEXUAL EN PUERTO RICO'
}

\author{
Luis E. Nieves Rosa \\ Sacha Pérez Acevedo ${ }^{3}$ \\ Coral Estrada Miranda \\ Melina Aponte Resto ${ }^{5}$ \\ Stephanie Ramirez $\mathrm{Cruz}^{\circ}$ \\ Verónica Silva Figueroa? \\ Melody Vélez Pérezs
}

\section{Resumen}

Esta investigación presenta los resultados de una encuesta sobre los incidentes de hostigamiento y conductas que pueden ser catalogadas como crímenes de odio en una muestra por disponibilidad de 86 lesbianas, hombres gay/homosexuales, bisexuales, transgénero y transexuales (LGBTT). Los resultados reflejan que la mayoría $(67.4 \%)$ reportaron haber sido víctimas

\footnotetext{
${ }^{1}$ Este proyecto fue parte un curso de un año (SOCl 4991-4992) del Proyecto de Adiestramiento en Investigación Social (PAIS) del Centro de Investigación Social Aplicada (CISA) del Departamento de Ciencias Sociales de la UPR-RUM.

${ }^{2}$ Docente, Departamento de Ciencias Sociales, Universidad de Puerto Rico, Recinto de Mayagüez.

${ }^{3}$ Estudiante graduada, Departamento de Psicología, Universidad de Puerto Rico, Recinto de Río Piedras.

${ }^{4}$ Estudiante Facultad de Derecho, Universidad Católica de Ponce.

${ }^{5}$ Estudiante, Departamento de Ciencias Sociales, Universidad de Puerto Rico, Recinto de Mayagüez.

${ }^{6}$ Estudiante, Departamento de Ciencias Sociales, Universidad de Puerto Rico, Recinto de Mayagüez.

${ }^{7}$ Estudiante, Departamento de Ciencias Sociales, Universidad de Puerto Rico, Recinto de Mayagüez.

${ }^{8}$ Estudiante, Departamento de Ciencias Sociales, Universidad de Puerto Rico, Recinto de Mayagüez.
} 
de hostigamiento y sufrido victimización por ser LGBTT. Dos terceras parte informaron haber recibido insultos verbales desde los 16 años hasta 12 meses antes de contestar la encuesta, y una cuarta parte reportó lo mismo en los últimos doce meses. Un poco más de una quinta parte dijo haber recibido golpes, patadas o agredido/a. Se analizan los datos a la luz de la Ley 46 del 4 de marzo de 2002 conocida como la Ley de agravantes por Crímenes de Odio. Se presentan recomendaciones para la profesión de trabajo social y otras profesiones para insertarnos en la lucha para erradicar la injusticia social.

[Descriptores: hostigamiento, crímenes de odio, orientación sexual, identidad de género].

\section{Abstract}

This research presents the results of a survey about incidents of harassment and victimization behaviors that can be classified as hate crimes in a non-random sample of 86 lesbian, gay men, bisexuals, transgender and transsexual (LGBTT). The results reflect that most of them $(67.4 \%)$ reported having been victims of harassment and victimization as LGBTT. Two third reported having received verbal insults directed at them since age 16 up to 12 months before answering the survey and one-quarter reported the same in the last twelve months. A little more than one-fifth reported that it had received punches, kicks or had been attacked. We analyze the data in the light of the Puerto Rican Law No. 46 from March 4, 2002, known as the Hate Crimes Law. Recommendations for the social work and other Human Service professions to eradicate social injustice are provided.

[Keywords: harassment, hate crimes, sexual orientation, gender identity]

\section{Introducción}

En Puerto Rico, el 4 de marzo de 2002 se aprobó la Ley 46 a los fines de enmendar las Reglas de Procedimiento Criminal de 1963 añadiendo un apartado ( $r$ ) al inciso A para considerar como agravante el hecho de que cualquier delito en contra de una persona haya sido motivado por prejuicio hacia la misma. Específicamente, dice: “(r) El delito fue cometido motivado por prejuicio hacia y contra la víctima por razón de raza, color, sexo, orientación sexual, género, identidad de género, origen, origen étnico, estatus civil, nacimiento, impedimento físico y/o mental, condición social, religión, edad, creencias religiosas o 
políticas. Para propósitos de establecer motivo como se dispone en este inciso, no será suficiente probar que el acusado posee una creencia particular, ni probar que el acusado meramente pertenece a alguna organización particular" (Lexjuris, 2012). Desde la aprobación de esta Ley hasta el 10 de marzo de 2011 no se había procesado a nadie aplicándole dichos agravantes. Razón por la cual el Senado de Puerto Rico aprobó el 10 de noviembre de 2011 un proyecto (PS 2021) que pretendía eliminar los agravantes relacionados con los crímenes de odio motivados por prejuicio por razón de orientación sexual, identidad sexual, género, identidad de género y etnicidad o nacionalidad descritos en el Capítulo II, Sección Segunda, Artículo 66. Circunstancias agravantes del Código Penal de 2004 (OSL, 2012). Dicho proyecto no fue aprobado en la Cámara de Representantes. Esto es solo un ejemplo de cómo el proceso de legislar leyes que garanticen la equidad y justicia social para toda la ciudadanía es un proceso de vaivenes políticos de los cuales todos y todas debemos estar atentos para expresarnos oponiéndonos a aquellas medidas que limitan nuestro ejercicio de ciudadanía o apoyando aquellas que garantizan nuestro derechos y proveen protecciones para los grupos más vulnerables.

\section{Antecedentes}

En Puerto Rico, las autoridades pertinentes han fallado en crear el protocolo adecuado con criterios claros para establecer cuando los crímenes son cometidos por prejuicio hacia y contra la victima por razón de sexo, orientación sexual, identidad sexual, género, identidad de género, origen, y origen étnico, lo que repercute en que no se lleven estadísticas de este tipo de crimen. En los Estados Unidos existe la Coalición Nacional de Proyectos en contra de la Violencia (NCAVP, por sus siglas en inglés) que recoge estadísticas sobre los crímenes de odio por orientación sexual, identidad sexual, género e identidad de género en 16 ciudades de 15 estados en los Estados Unidos. Según el informe de 2011, los crímenes de odio aumentaron de 27 en el 2010 a 30 en el 2011. Un incremento de $11 \%$. Este aumento refleja el más alto índice de asesinatos reportados por el NCAVP. El informe de 2012 mostró una merma de 4\% en comparación con el 2011 (2,092 a 2,016 de casos reportados). Aun así sigue siendo el cuarto número de incidentes más alto reportado por la NCAVP (NCAVP, 2012). Estos programas recogen datos de todo tipo de violencia de la que son objeto las personas por su orientación 
sexual, identificación sexual e identidad de género. En Puerto Rico, aún con esta ley, no se ha operacionalizado un programa para recoger este tipo de estadísticas.

\section{Estadísticas}

Solo tenemos conocimiento de dos trabajos publicados que recogen este tipo de incidentes con la población de lesbianas, hombres gay, personas bisexuales, transgénero y transexuales. En un estudio realizado por el Dr. José Toro Alfonso para la Comisión de Derechos Civiles de Puerto Rico, con una muestra de 929 personas gay, lesbianas, bisexuales, transgénero y transexuales (LGBTT), el 63.6\% informó que recibieron insultos por razón de su orientación sexual, $17.7 \%$ que le habian tirado objetos por razón de su orientación sexual, $11.5 \%$ que habian recibido golpes o patadas por su orientación sexual, $32.1 \%$ sentir temor por sus vidas en lugares públicos y $56.6 \%$ han tenido la experiencia de ser molestados/as por compañeros de trabajo. Además ese mismo estudio reflejó que un $30 \%$ de los/ as participantes reportaron haber tenido experiencias de rechazo con la Policía, $9 \%$ en dependencias de Tribunales y Justicia, y $8 \%$ en dependencias del Departamento de la Familia (Toro Alfonso, 2007). El segundo estudio realizado por Rivera Quiñónez, Toro Alfonso y Meléndez (2013) con 103 personas LGBTT encontró que, el $73 \%$ reportó sentirse inseguro(a) por su orientación sexual ante el alza de la criminalidad en la Isla. El $44 \%$ dijo sentir temor por su vida en un lugar público.

Estos datos reflejan que este sector de la sociedad es una población vulnerable y que se encuentra a la merced de la violencia directa. Según Galtung (1969), la violencia directa constituye todas aquellas acciones físicas, emocionales y psicológicas hacia una persona, grupo o comunidad causados y sancionados por el efecto de la violencia cultural. Según él, la violencia cultural son "todos aquellos aspectos que tienen que ver con la cultura, como: religión, ideología, lenguaje, arte y ciencias, y que pueden ser utilizados para justificar o legitimar la violencia directa o estructural" (pág. ). Se manifiesta en las costumbres, rituales y valores sociales, chistes, historias, películas, anuncios, comedias y novelas, entre otros, y forman parte del marco conceptual e ideológico que valida o normaliza la violencia directa. La violencia cultural puede fomentar la violencia social colectiva hacia algunos sectores de la sociedad (OMS, 2003). A su vez, esta se encuentra enraizada en todas las estructuras sociales, 
normalizada e institucionalizada por la experiencia y el uso de la costumbre. Esto se conoce como la violencia estructural, término que fue utilizado por primera vez durante la década de los 60 por Galtung (1969) para hacer referencia a la violencia sistémica que existe en las diferentes instituciones y estructuras sociales; y que puede llegar a matar a las personas al prevenir que estas alcancen satisfacer sus necesidades básicas. Algunos ejemplos de la violencia institucional son: el elitismo, el etnocentrismo, el clasismo, el racismo, el sexismo, el heterosexismo y la homofobia, el nacionalismo, y el discrimen por razón de edad, entre otros. La violencia estructural ocurre siempre que las personas estén en desventaja política, legal, económica o por tradiciones culturales para alcanzar satisfacer sus necesidades básicas.

La realidad es que los incidentes de hostigamiento y crímenes de odio por orientación sexual solo se han comenzado a reportar por iniciativas de organizaciones LGBTT que han levantado la suficiente documentación como para cabildear a nivel local, estatal y federal para que se legislaran leyes en contra de estos crímenes. Ejemplo de estas son el National Gay and Lesbian Task Force (NGLTF) y la NCAVP (Berrill, 1992). Herek (1992) plantea que la heterosexualidad como norma cultural hace que la homosexualidad se invisibilice en la sociedad y que cuando esta se hace visible es usualmente condenada y estigmatizada. Además, plantea que esta alternancia entre la invisibilidad y hostilidad se debe a cuatro instituciones sociales: la religión, las leyes, la psiquiatría y la psicología, y los medios de comunicación. Podemos ver entonces que Herek (1992) coincide con Galtung (1969) al identificar los elementos sociales que forman el caldo de cultivo para que se sancione la violencia hacia un sector de la población -las personas LGBTT- desde la cultura y las instituciones sociales.

\section{Marco teórico}

El marco teórico que guía esta investigación está fundamentado en las teorías de Galtung (1969) y Herek (1992). Según Galtung (1969), la sociedad a través de la cultura y sus instituciones facilita una conducta violenta hacia personas, grupos y comunidades que no conforman las normas sociales y culturales hegemónicas de la sociedad, facilitando así que sean más vulnerables a ser víctimas de violencia directa. Para Herek (1992) este tipo de violencia directa es facilitada cuando la heterosexualidad se adopta como la norma cultural hegemónica 
de la sociedad y se valida social y culturalmente en cuatro instituciones fundamentales de la sociedad: la religión, las leyes, la psiquiatría y la psicología, y los medios de comunicación (Herek, 1992).

\section{Objetivo}

Ante la incapacidad de las agencias gubernamentales de recoger estadísticas sobre este tipo de crimen, nos planteamos explorar y describir cuál es la incidencia del hostigamiento y crímenes de odio por orientación sexual prevaleciente entre las personas LGBTT en Puerto Rico. Este estudio se suma al acervo de investigaciones (Toro Alfonso, 2007; Rivera Quiñonez, Toro Alfonso \& Meléndez, 2013) que han comenzado a documentar este tipo de incidentes en la población LGBTT en Puerto Rico.

\section{Método}

\section{Diseño}

El diseño utilizado para esta investigación es de corte exploratorio y descriptivo (Hernández Sampierri, Fernández Collado, \& Baptista Lucio, 2010). Es exploratorio ya que I nos interesa es explorar la incidencia del hostigamiento y crímenes de odio por orientación sexual de la que son objeto las personas LGBTT. Es descriptivo porque nos interesa describir las instancias en que las personas de la comunidad LGBTT sufren de abuso físico, emocional o verbal por su orientación sexual.

\section{Instrumento}

Para esta investigación se utilizó un cuestionario cuantitativo autoadministrado. El instrumento utilizado para la recolección de datos fue un cuestionario autoadministrable en línea a través de la plataforma de Qualtrics ${ }^{\circledR}$. El mismo incluyó dos instrumentos: 1) datos demográficos; y 2) una adaptación de la encuesta del inventario de violencia y victimización antigay de Herek y Berrill (1992).

\section{Datos demográficos}

Se les preguntó la edad, si se identificaba como hombre, mujer, transgénero/transexual, su identidad nacional, nivel más alto de escolaridad alcanzado, orientación sexual: homosexual/ lesbiana, bisexual; su situación de empleo, ingresos, situación de vivienda, si se considera una persona religiosa, con qué grupo religioso se identifica, cuán importante es la religión en su vida y 
con qué frecuencia participa de actividades religiosas.

\section{Encuesta de violencia y victimización anti-gay}

Esta encuesta consta de doce premisas de experiencia de hostigamiento y victimización. Se le preguntó que contestaran utilizando una escala de $0=$ Nunca, $1=$ Una vez y $2=2$ o más veces si habían experimentado alguna experiencia de hostigamiento y victimización porque alguien percibió que era LGBTT. Primero, se les preguntó para los últimos 12 meses y segundo, desde los 16 años hasta hace doce meses atrás. Además, se les pidió que identificara el sexo y edad de la persona o personas atacantes, la etnicidad o nacionalidad, si eran extraños/as o personas conocidas, si necesitó ayuda médica después del incidente, si trataronde buscarla, en qué ciudad o pueblo le ocurrió, si reportaron el incidente a la policía, y cuál fue su repuesta. Para esta pregunta se les proveyó una lista de posibles repuestas que fluctuaban desde sensitiva hasta homofóbica. También se les preguntó si lo habían notificado a alguna organización de la comunidad, y si el incidente le había afectado como actúa o se comporta en público. Si contestaban que sí, se les pedía que explicaran. Por último, se les pidió que contestaran una serie de aseveraciones relacionadas al impacto que las experiencias de victimización han tenido en la conducta que tienen en lugares públicos, utilizando la escala de $0=$ Nunca, $1=$ Una vez y $2=20$ más veces para los últimos 12 meses y luego desde los 16 años hasta hace doce meses atrás.

\section{Población}

El criterio de participación los/as participantes era que debían ser hombres y mujeres, o personas que se identificaran como transgénero/transexuales, de orientación sexual lésbica, gay/homosexual o bisexual mayores de 21 años y residentes de Puerto Rico.

\section{Procedimiento}

Luego de preparado el cuestionario se sometió al Comité para la Protección de los Seres Humanos en la Investigación (CPSHI) de la Universidad de Puerto Rico, Recinto de Mayagüez para su autorización (CPSHI/IRB 00002053). Una vez aprobado, se procedió a subir el cuestionario en la plataforma Qualtrics ${ }^{\circledR}$ y enviarse vía correo electrónico a diversas organizaciones que proveen servicios a la población LGBTT y otras organizaciones 
de carácter social o de activismo de la comunidad. Una vez el/la participante accede el enlace encontraba un mensaje de bienvenida explicando el objetivo del estudio y la hoja de consentimiento informado. La Hoja de Consentimiento Informado contenía información acerca del propósito del estudio, los riesgos y beneficios relacionados a la confidencialidad y los estándares de investigación y los derechos que como participante tiene de desistir a completarlo en cualquier momento. Si la persona aceptaba participar del estudio debía presionar la opción de ACEPTO, para poder pasar al cuestionario. Si por el contrario la persona, presionaba la opción de NO ACEPTO, el programa la llevaba a una página de despedida dándole las gracias.

\section{Muestra}

La selección de la muestra fue por disponibilidad y voluntaria, utilizando la técnica de bola de nieve a través de las redes cibernéticas. Se contactaron diversas organizaciones que proveen servicios a la comunidad LGBTT como COAl, Inc. y CARIB; y otras como Puerto Rico para Tod@s, para que promovieran el enlace por sus redes. Un total de 145 personas accedieron al enlace, de esas 121 (83\%) completaron la encuesta. De los/as que completaron la encuesta eliminamos 24 porque no cumplían con el criterio de edad para participar en el estudio. Otros once se eliminaron porque con no cumplían con el criterio de orientación sexual LGBTT, ya que contestaron que eran heterosexuales. Los resultados que presentamos a continuación corresponden a las 86 personas que cumplían con el criterio de participación y contestaron el cuestionario.

\section{Hallazgos}

\section{Características demográficas}

La edad de la muestra fluctuó de los 21 a 70 años de edad. La edad promedio fue de 29.41 años de edad, con una desviación estándar de 11 años. La mayoría (93\%) informó ser de nacionalidad puertorriqueña, la mitad $(50 \%)$ son estudiantes universitarios/as. En la premisa sobre la religión, la mayoría $(53.5 \%)$ indicó no practicar ninguna religión, una cuarta parte $(25.6 \%)$ indicó identificarse con la religión católica, mientras que una quinta parte $(20.9 \%)$ se identificaba con otras religiones. En la Tabla 1 se presentan los datos relacionados al sexo de los/ as participantes. La mayoría de las personas que participaron fueron hombres. 
Tabla 1. Sexo de los y las participantes $(n=86)$

\begin{tabular}{lcc}
\hline Sexo & $\mathrm{n}$ & $\%$ \\
\hline Hombre & 57 & 66.3 \\
Mujer & 27 & 31.4 \\
Transgénero/transexual & 2 & 2.3 \\
\hline
\end{tabular}

En la tabla 2 presentamos la orientación sexual de los y las participantes. La mayoría se identificaron como homosexuales y lesbianas. Cuatro personas marcaron la opción otro y escribieron: queer, pansexual, transexual.

Tabla 2. Orientación Sexual $(n=86)$

\begin{tabular}{lcc}
\hline Sexo & $\mathrm{n}$ & $\%$ \\
\hline Homosexual/lesbiana & 67 & 77.9 \\
Bisexual & 15 & 17.4 \\
Otro & 4 & 4.7 \\
\hline
\end{tabular}

En la gráfica 1 le presentamos el nivel de educación de los y las participantes. La mayoría informa tener educación universitaria $(n=86)$.

\section{Gráfica 1. Nivel de educación}

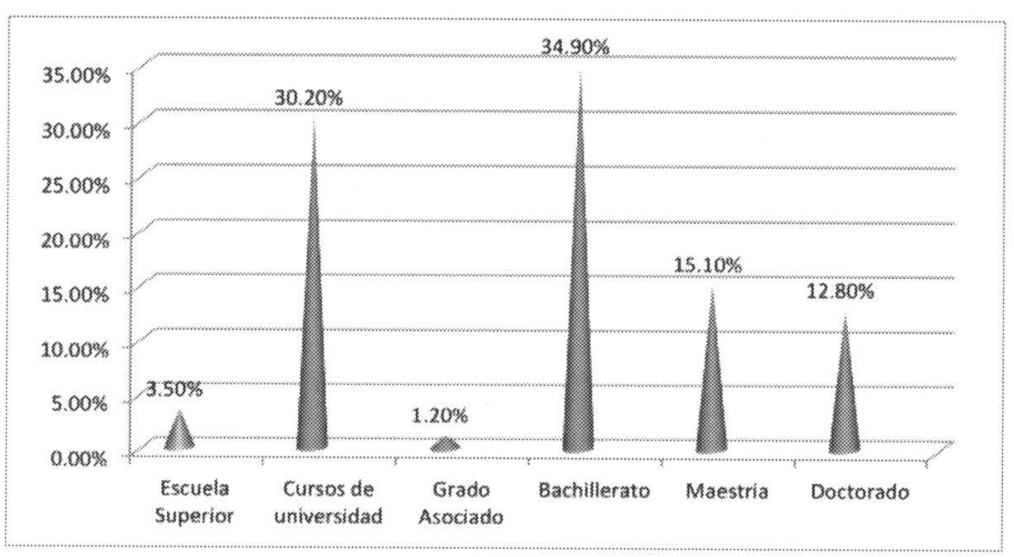


En la gráfica 2 presentamos la situación que mejor describe la situación de trabajo de los y las participantes. La mayoría son estudiantes a tiempo completo. Las personas que respondieron 'otro' indicaron que estaban retirados/as (2), buscando (1), estudio y trabajo (2) y por su cuenta (1).

Gráfica \# 2. Situación de empleo $(n=86)$.

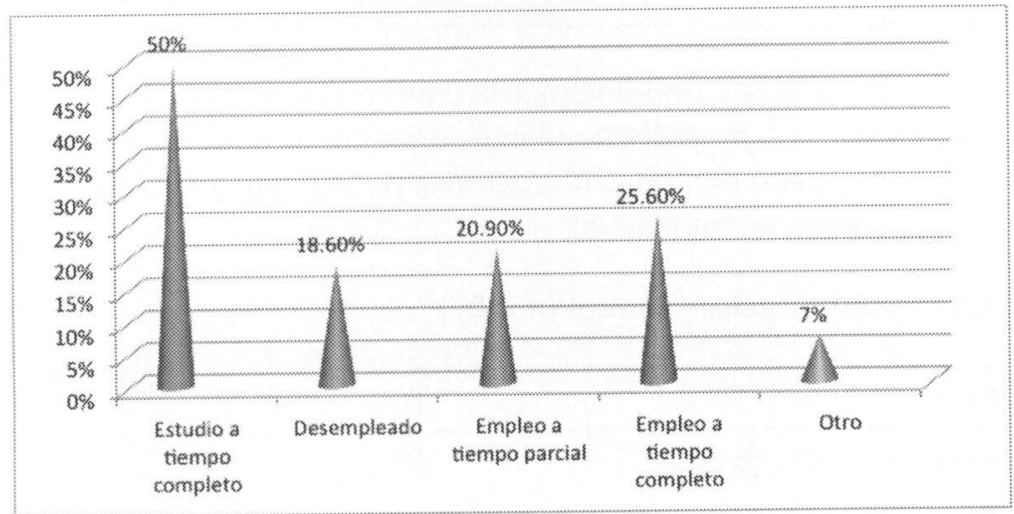

En la Gráfica 3 presentamos los ingresos de los y las participantes. La mayoría ganan menos de $\$ 10.000$ dólares anuales.

Gráfica \# 3. Ingreso ( $n=86)$.

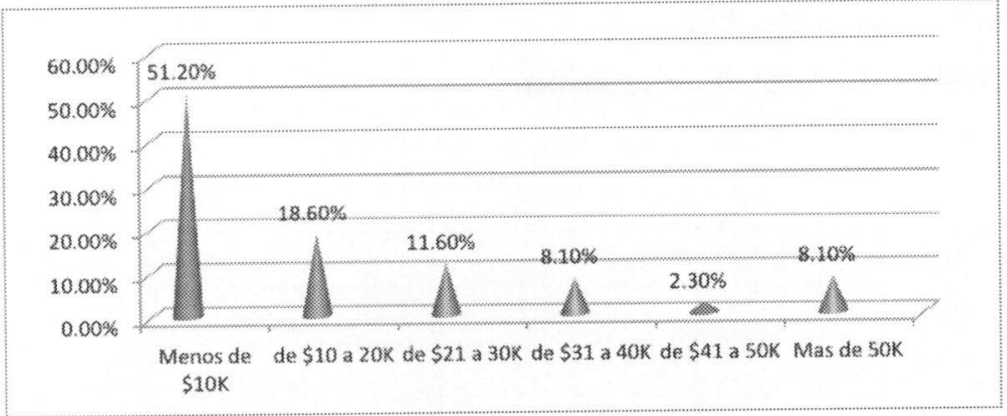

\section{Situación de vivienda}

La mayoría $(48.80 \%)$ vive en una casa o apartamento alquilado, seguido de con padres y/o familiares $(32.60 \%)$, apartamento o casa propia (15.10\%) y amistades $(3.50 \%)$. 


\section{Experiencias de hostigamiento y victimización}

En la siguiente tabla presentamos los datos relacionados a incidentes de hostigamiento y victimización por ser LGBTT, en los últimos doce meses y desde los 16 años de edad, hace doce meses. Presentamos la suma de los datos agregados de una vez y dos o más veces. En general $62(72.1 \%)$ de las personas reportaron haber sido víctima de incidentes de hostigamiento victimización por ser LGBTT. De esas, solo $4(.06 \%)$ reportaron el incidente a un agente del orden público.

\section{Tabla 3. Experiencias de hostigamiento y victimización porque alguien percibió que era LGBTT. $(n=86)$}

\begin{tabular}{|c|c|c|c|c|c|}
\hline \multirow{2}{*}{\multicolumn{2}{|c|}{$\begin{array}{l}\text { ¿Porque alguien pensaba que eras } \\
\text { LGBTT... }\end{array}$}} & \multicolumn{2}{|c|}{$\begin{array}{l}\text { Últimos } 12 \\
\text { meses }\end{array}$} & \multicolumn{2}{|c|}{$\begin{array}{l}\text { Desde los } 16 \\
\text { años hasta } 12 \\
\text { meses atrás }\end{array}$} \\
\hline & & \multirow{2}{*}{$\frac{n}{24}$} & \multirow{2}{*}{$\begin{array}{c}\% \\
27.9\end{array}$} & \multirow{2}{*}{$\frac{n}{57}$} & \multirow{2}{*}{$\begin{array}{c}\% \\
66.3\end{array}$} \\
\hline 1. & ...te han dirigido insultos verbales? & & & & \\
\hline 2. & $\begin{array}{l}\text {... han golpeado, pateado o } \\
\text { agredido? }\end{array}$ & 3 & 3.6 & 19 & 22.5 \\
\hline 3. & $\begin{array}{l}\text {...te han sacado de una vivienda/un } \\
\text { apartamento/hospedaje? }\end{array}$ & 1 & 1.2 & 5 & 5.8 \\
\hline 4. & $\begin{array}{l}\text {... algún compañero/a te ha } \\
\text { molestado por tu orientación sexual? }\end{array}$ & 20 & 23.3 & 45 & 52.3 \\
\hline 5. & $\begin{array}{l}\text {...se negaron a atenderte en una } \\
\text { agencia de gobierno? }\end{array}$ & 5 & 5.9 & 6 & 6.3 \\
\hline 6. & ... te han tirado con algún objeto? & 4 & 4.7 & 17 & 20 \\
\hline 7. & $\begin{array}{l}\text {... te han corrido o perseguido de } \\
\text { algún lugar? }\end{array}$ & 6 & 7.0 & 13 & 15.1 \\
\hline 8. & $\begin{array}{l}\text {...has sido hostigado/a por una } \\
\text { agente del orden público? }\end{array}$ & 7 & 8.1 & 13 & 15.1 \\
\hline 9. & $\begin{array}{l}\text {...has sentido temor por tu vida en } \\
\text { un lugar público? }\end{array}$ & 21 & 24.8 & 32 & 37.2 \\
\hline 10. & $\begin{array}{l}\text {...un agente del orden público te ha } \\
\text { tratado diferente? }\end{array}$ & 11 & 12.8 & 22 & 25.6 \\
\hline 11. & $\begin{array}{l}\text {...un/a empleado/a de agencia } \\
\text { gubernamental te ha tratado } \\
\text { diferente? }\end{array}$ & 8 & 9.3 & 15 & 17.4 \\
\hline 12. & $\begin{array}{l}\text {...un/a agente del orden público o } \\
\text { empleado de agencia del gobierno } \\
\text { se ha reído y burlado de ti? }\end{array}$ & 17 & 20 & 26 & 30.2 \\
\hline
\end{tabular}




\section{Datos de los/as perpetradores/as}

El $52.3 \%$ indicó que las personas que le atacaron $u$ hostigaron fueron hombres y el $43 \%$ mujeres, mientras que el $30 \%$ indicó que desconocía su sexo. Los datos aquí presentados no suman 100 , ya que la pregunta estaba diseñada para que contestaran si conocían el sexo de las personas que le atacaron tomando en consideración que podía ser más de una persona. Según los/as participantes, la edad de la mayoría de los/as perpetradores/as fluctuó entre los 13 y 40 años de edad. El 62\% de los/as perpetradores/as fueron extraños, mientras que el $58 \%$ eran personas conocidas. Solo $4(.6 \%)$ de las personas indicaron que necesitó ayuda médica después del incidente. De ese número solo 3 personas buscaron ayuda médica.

\section{Lugar donde sucedió el incidente}

Los lugares donde sucedieron los incidentes lo dividimos en cinco áreas: El $35 \%$ informó que el incidente les ocurrió en el área metropolitana (incluye: Carolina, Bayamón, Guaynabo, San Juan y Toa Baja); $7 \%$ en el área Este (incluye: Humacao, Yabucoa, Naguabo); y Sur (incluye: Salinas, Juana Díaz y Ponce); 16\% en el área Centro (Incluye: Aibonito, Barranquitas, Caguas, Cayey, Corozal, Juncos y Morovis); y $42 \%$ en el área Oeste (incluye: Aguada, Aguadilla, Cabo Rojo, Guánica, Lares, Mayagüez y San Sebastián).

\section{Reportó el incidente a la policía}

Del total de 86 participantes $62(72.1 \%)$ reportaron algún incidente desde los 16 años hasta 12 meses atrás y en los últimos doce meses. De esos solo 4 reportaron el incidente a la policía. En la tabla 4 presentamos como fue la repuesta de la policía.

Tabla 4. Repuesta de la policía hacia el/la querellante $(n=4)$.

\begin{tabular}{lcccc}
\hline \multirow{2}{*}{ La policía fue... } & \multicolumn{2}{c}{ Últimos 12 meses } & \multicolumn{2}{c}{$\begin{array}{c}\text { Desde los } 16 \text { años hasta } \\
\text { hace } 12 \text { meses atrás }\end{array}$} \\
\cline { 2 - 5 } & $\mathrm{n}$ & $\%$ & $\mathrm{n}$ & $\%$ \\
\hline Sensitiva & 0 & 0 & 0 & 0 \\
Indiferente & 4 & 100 & 4 & 100 \\
Hostil & 3 & 75 & 3 & 75 \\
Amenazante & 2 & 50 & 1 & 25 \\
Profesional & 1 & 25 & 0 & 0 \\
Abusiva & 2 & 50 & 1 & 25 \\
Eficiente & 0 & 0 & 0 & 0 \\
Servicial & 0 & 0 & 0 & 0 \\
Homofóbica & 3 & 75 & 1 & 25 \\
\hline
\end{tabular}


A las personas que respondieron que no reportaron el incidente a la policía, se les solicitó que explicaran por qué no lo reportaron. A continuación presentamos algunas de sus repuestas:

\section{Relacionadas con policías:}

"El hostigamiento y ataque en los lugares de encuentro o cruising fue de parte de oficiales de la Policía".

"El último incidente fue con un policía, los anteriores fueron en la escuela y los resolví hablando, era menor y tenía miedo".

"Era muy joven y en algunas ocasiones eran los mismos policías".

"Fue un policía".

"Porque fue la policía quien vino a intentar sacarme".

"No lo encontré pertinente, ya que fue con la misma policía".

\section{En la escuela:}

"Como tal a la policía no, pero si a los oficiales escolares, entiéndase consejeros. Tomaron el asunto en sus manos y los acosos se detuvieron". "Fue en la escuela, se llevó a la oficina del Director".

"Fueron insultos y comentarios, lo reporté a la Directora de la escuela".

"Los ataques físicos fueron en la escuela, no conocía los recursos disponibles para reportar el asunto. Era una época donde al acoso escolar no se le daba prioridad como ahora".

"Se habló con la Principal y me mandaron a un psicólogo para que me controlara los manerismos".

\section{Con extraños:}

"El incidente fue saliendo de la playa con heterosexuales, no pasó a mayores, empujones 
y amenazas".

"Fue verbal, no lo tomé personal, son ignorancias

de los jóvenes de esa edad".

"Miedo a burlas"

"No fue ataque físico, solo insultos"

"No fue uno grave".

\section{Con conocidos:}

"Era una persona que conocía personalmente y no quise involucrar a nadie más".

"No hacía falta. Son solo palabras de parte de algunos compañeros".

\section{Impacto que las experiencias de victimización han tenido en la conducta que tiene en lugares públicos}

En la tabla 5 presentamos los datos del impacto que han tenido las experiencias de victimización en diferentes aspectos de su vida.

Tabla \# 5. Impacto $(n=86)$.

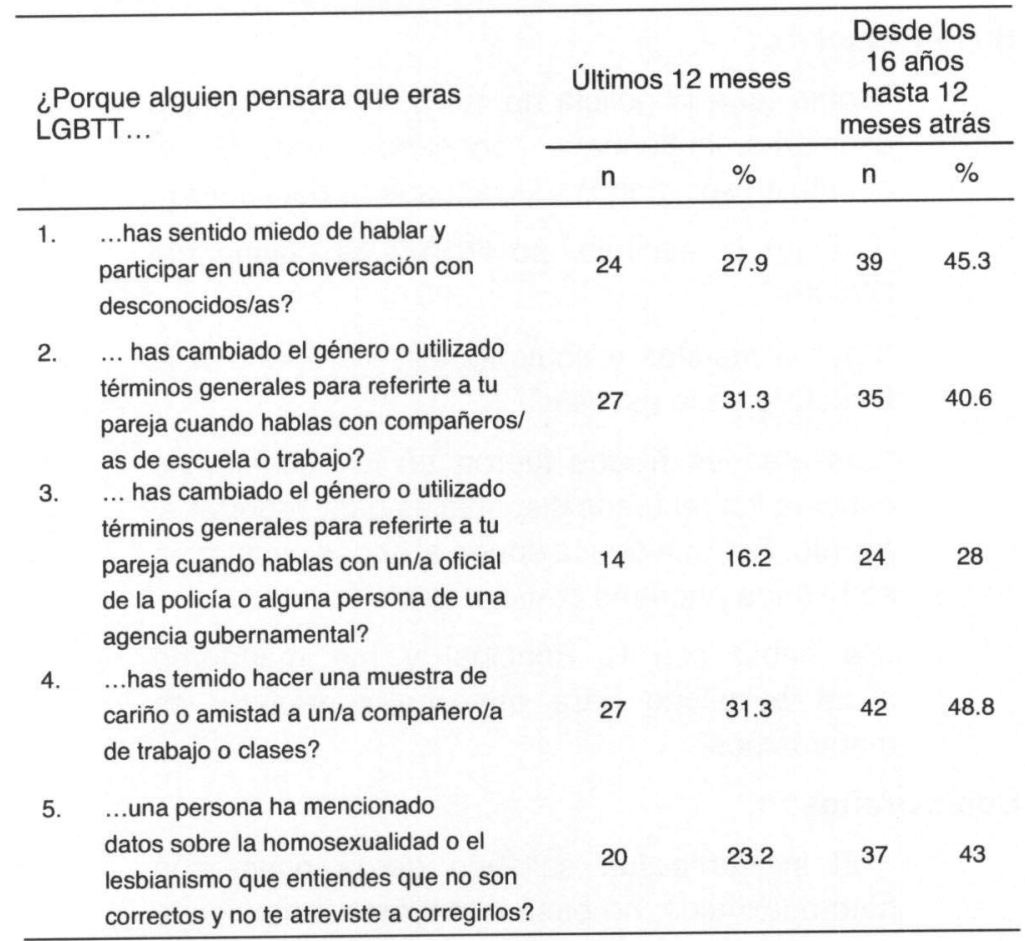




\section{Discusión}

Los datos demográficos de esta muestra tienden a ser similares a los encontrados por Toro Alfonso (2007) y Rivera Quiñones, Toro Alfonso y Meléndez (2013) en relación a la identidad sexual ya que la mayoría de quienes contestaron fueron hombres, seguidos por las mujeres y solo dos personas que se identificaron como transgénero o transexual. En relación a la orientación sexual encontramos igual similitud siendo la mayoría mujeres lesbianas y hombres gay/homosexuales cuando les comparamos con quienes se identificaron como bisexuales. En relación a la edad, los y las participantes de esta muestra tienden a ser relativamente más jóvenes reportando una edad media promedio de 29.41 en comparación con las muestras Toro Alfonso (2007) y Rivera Quiñones, Toro Alfonso y Meléndez (2013) cuya edad promedio reportada fue de 35 años de edad. Al igual que en los estudios mencionados la mayoría de esta muestra es de nacionalidad puertorriqueña. En términos de educación, esta muestra se parece más a la de Rivera Quiñones, Toro Alfonso y Meléndez (2013) ya que tienen un bachillerato de universidad o se encuentran realizando estudios universitarios en comparación con la muestra de Toro Alfonso (2007) cuya mayoría reportó tener estudios graduados. Ahora bien, en términos generales, podemos decir que es una población educada al igual que la reportada por Toro Alfonso (2007) y Rivera Quiñones, Toro Alfonso y Meléndez (2013). La diferencia mayor la encontramos en relación al ingreso y empleo, ya que esta muestra en su mayoría son estudiantes universitarios a tiempo completo cuyos ingresos oscilan alrededor de los $\$ 10,000.00$ dólares anuales o menos.

\section{Experiencias de hostigamiento y victimización}

En relación a las experiencias de hostigamiento y victimización, los resultados de este estudio son similares ya que el $66.3 \%$ de los y las participantes reportaron haber sido víctimas de insultos verbales por su orientación sexual desde los 16 años hasta hace doce meses atrás y $27.9 \%$ en los últimos doce meses en comparación con el $63 \%$ en toda su vida según reportado por Toro Alfonso (2007) y el $58 \%$ según reportado por Rivera Quiñones, Toro Alfonso y Meléndez (2013). Esto muestra que la población LGBTT es vulnerable a ataques verbales no solamente en la adultez, sino que también desde la adolescencia. Mientras que solo el $11.5 \%$ de la muestra de Toro Alfonso (2007) reportó 
haber recibido golpes o patadas por su orientación sexual, y el $10.6 \%$ en la de Rivera Quiñones, Toro Alfonso y Meléndez (2013), el $22.5 \%$ de los y las participantes de esta muestra informó haber recibido golpes, patadas o agresiones físicas desde los 16 años hasta hace doce meses atrás y el $3.6 \%$ en los últimos doce meses. En este caso encontramos que los resultados de este estudio duplican los encontrados en Toro Alfonso (2007) y Rivera Quiñones, Toro Alfonso y Meléndez (2013). En términos a la percepción de vulnerabilidad y sentir temor por sus vidas en lugares públicos, los resultados tienden a ser similares $37.2 \%$ desde los 16 años hasta hace doce meses y $24.8 \%$ en los últimos doce meses cuando los comparamos con el $32.1 \%$ reportado por Toro Alfonso (2007) y el $44.1 \%$ reportado por Rivera Quiñones, Toro Alfonso y Meléndez (2013). En relación a ser hostigados/ as por personas conocidas como compañeros/as de trabajo o escuela, los resultados tienden a ser similares. Encontramos que un $52.3 \%$ fue hostigado/a por un/a compañero/a de trabajo/ escuela desde los 16 años hasta hace 12 meses y $23.3 \%$ en los últimos 12 meses, en comparación con el $56.6 \%$ de la muestra de Toro Alfonso (2007) y el 62\% de Rivera Quiñones, Toro Alfonso y Meléndez (2013).

\section{Datos de los/as perpetradores/as}

Los datos de este estudio plantean la necesidad de un cambio de paradigma en la mayoría de nuestras instituciones sociales. Solo así podremos transformar nuestra cultura de una violenta hacia una pacífica. Los datos de este estudio reflejan que la edad de los/as perpetradores/as oscila entre los 13 a 40 años de edad. Estamos hablando de una población joven. Para romper con este ciclo debemos comenzar a elaborar campañas generales por el respeto a los derechos humanos y a la diversidad sexual, con mensajes claros desde una perspectiva de derechos humanos sobre lo que es la orientación sexual e identidad sexual a través de los medios de comunicación y en los currículos escolares. Por otro lado, la Policía tiene que comenzar a educar a sus agentes en relación al respeto de los derechos humanos y a la no violación de los derechos civiles. Los datos de esta investigación señalan que, del total de personas que reportaron algún incidente solo cuatro lo reportaron a la policía y de esos, nadie reportó que su repuesta haya sido sensitiva, eficiente o servicial. Solo uno la encontró profesional. En su mayoría la encontraron indiferente, hostil, amenazante, abusiva y homofóbica. No es por casualidad 
u omisión que las personas LGBTT prefieren minimizar lo que les sucede y no reportarlo a la policía. Resulta ser un mecanismo de defensa para no ser revictimizados/as por los mismos/as agentes a quienes les corresponde protegerles.

Estos resultados demuestran, como en las investigaciones de Toro Alfonso (2007) y Rivera Quiñones, Toro Alfonso y Meléndez (2013) que, la población de personas LGBTT es una población altamente vulnerable a conductas de hostigamiento y victimización por el mero hecho de ser personas con una orientación sexual e identidad de género diferente a la sancionada social y culturalmente por las instituciones de nuestra sociedad. El hecho de que recientemente se haya legislado para incluir la protección de las personas LGBTT en algunas leyes, como la Ley 46 del 4 de marzo de 2002, la Ley 22 o la Ley 23 del 23 de mayo de 2013 , no garantiza que esta población no esté a la merced de ser víctimas de violencia verbal, psicológica o física. Las leyes, tal y como se legislan y aprueban, no tienen un componente de educación y compromiso para cambiar las estructuras sociales y culturales que hacen falta para transformar nuestra sociedad en una más equitativa y justa donde se respete el derecho a la diversidad. Si analizamos las mismas, aunque incluyen bajo su protección a un sector de la sociedad que ha sido eternamente invisibilizado, estas son en esencia preponderantemente punitivas. Buscan el castigo después de ocurrido el hecho. Como sociedad debemos aspirar a que no ocurra el hecho. Por lo tanto, corresponde a las profesiones de la conducta, a educadores y educadoras asumir la responsabilidad de educar para el respeto por los derechos humanos de todas las personas. Hay que hacer un esfuerzo para cambiar las estructuras sociales que como nos señalara Galtung (1969) y Herek (1992) facilitan una cultura que facilita la violencia directa hacia los sectores más vulnerables de la sociedad.

Para lograr esto tenemos que comenzar con la educación desde temprana edad, la educación centrada desde los derechos humanos y por el respeto a la diversidad. En torno a las leyes, hay que trabajar con las instituciones responsables de hacer valer las mismas: la Policía, el Departamento de Justicia y la Administración de Tribunales. 
En relación a la profesión de Trabajo Social, debemos adherirnos a nuestro Código de Ética (2011), el cual establece en Canon I, Artículo 1, inciso f:

"Nodiscriminarápormotivosderaza, color, género, estado civil, edad, origen étnico, ocupación, nacionalidad, necesidades especiales, ideología religiosa/ prácticas religiosas, ideología política, condición de salud, física y mental, condición social, afiliación sindical, orientación sexual, tipos de familias, circunstancias o por cualquier otra razón en la prestación de los servicios" (pág.

22).

En el canon II, Artículo 1, inciso f: "Evitará prácticas discriminatorias o abusivas contra los participantes a quienes preste servicios, ni condonará tales prácticas cuando sean realizadas por otras personas. Esto incluye los grupos a los que no presta servicios en ese momento" (pág. 26).

Estos están directamente relacionados con el Valor de la Justicia Social el cuál plantea:

Principio Ético: Los y las profesionales del Trabajo Social reconocen la importancia de que sus actuaciones estén orientadas a la promoción, alcance y logro de la justicia social.

"Los y las profesionales del Trabajo Social prestarán atención y serán militantes para denunciar todo acto que amenace el derecho de las personas y los grupos a vivir en paz. Las actividades profesionales buscan promover sensibilidad y conocimiento acerca de la opresión y la diversidad cultural y étnica. Los profesionales del Trabajo Social se esforzarán para asegurar el acceso a la información necesaria, servicios y recursos; igualdad en oportunidad; y participación significativa en la toma de decisiones para todas las personas. Por tanto, las intervenciones de él y de la profesional de Trabajo Social estarán enmarcadas en la Justicia Social y el respeto a los Derechos Humanos" (Código de Ética, Pág. 18: CPTSPR, 2011).

La invitación es como indica López Ortiz (2012, Pág. 83) "...nuestra guía debe ser el reconocimiento de la diversidad 
sexual, la defensa de los derechos humanos y el disfrute equitativo de la justicia social". Los y las profesionales del trabajo social de puerto Rico tenemos el deber ético y profesional de pronunciarnos en aquellas instancias que algún grupo de la sociedad sufra discriminación y opresión. Por lo tanto, les invito a que a través del Comité LGBTT de la Comisión Permanente de Diversidad y Acción Social elaboremos esfuerzos conjuntos con otros sectores de la sociedad para detener el hostigamiento y victimización de la que es sujeto la población LGBTT. Solo así conseguiremos transformar las estructuras que fomentan la violencia hacia este sector de nuestra sociedad. 


\section{Referencias}

Berrill, Kevin T. (1992). Anti-Gay Violence and Victimization in the United States: An Overview. En Gregory M. Herek y Kevin T. Berrill (1992). Hate Crimes: Confronting Violence Against Lesbians and Gay Men. California: Sage Publications.

CDC (s.f.). ¿Qué es un Crimen de Odio? Estado Libre Asociado de Puerto Rico: Comisión de Derechos Civiles (CDC). Recuperado de www.derechoscivilespr.org

CPTSPR (2011). Código de Ética. Colegio de Profesionales del Trabajo Social de Puerto Rico [CPTSPR]: Autor

Galtung, Johan. (1969). Violence, Peace, and Peace Research, Journal of Peace Research, Vol. 6, No. 3. pp. 167-191.

Herek, Gregory, M. (1992). The Social Context of Hate Crimes: Notes on cultural heterosexism. En Gregory M. Herek y Kevin T. Berrill (1992). Hate Crimes: Confronting Violence Against Lesbians and Gay Men. California: Sage Publications.

Herek, Gregory M. \& Berril, Kevin T. (1992). Documenting the Victimization of Lesbian and Gay Men: Methodological Issues. En Gregory M. Herek y Kevin T. Berrill (1992). (Eds.). Hate Crimes: Confronting Violence Against Lesbians and Gay Men. California: Sage Publications.

Hernández Sampierri, Fernández Collado, \& Baptista Lucio. (2010). Metodología de la Investigación. (5ta Edición). México: McgrawHill

Lexjuris (2012). Ley Núm. 46 del año 2002. ELA: Autor. Recuperado de www.Lexjuris.com el 12 de Agosto de 2012.

López Ortiz, M.T. (2012). Diversidad Sexual: Estigma y Rechazo Social. En Mabel T. López Ortiz (Ed.). Diversidad Humana: Retos y Compromisos del Trabajo Social. San Juan: Publicaciones Puertorriqueñas.

NCAPV (2013). Lesbian, gay, bisexual, Transgender, Queer and HIVAffected hate Violence in 2012. USA: A Report from the National Coalition of Anti-Violence Programs. Recuperado de www. nacavp.org

OMS (2003). Primer Informe Mundial sobre la Violencia y la Salud. Organización Mundial de la Salud (OMS). Recuperado de www. paho.org el 1 de agosto de 2011.

OSL (2012). Proyecto del Senado 2021 del 10 de marzo de 2011. Recuperado de www.osl.gov el 12 de agosto de 2012.

Rivera Quiñonez, Christian, Toro Alfonso, José, \& Meléndez, Lymari (2013). Minorias frente al alza en la criminalidad: percepción de seguridad de la comunidad lesbiana, gay, bisexual y transgénero (LGBTT) en Puerto Rico. Revista Puertorriqueña de Psicología, 24, 1-14.

Toro Alfonso, José. (2007). Por la Vía de la Exclusión: Homofobia y Ciudadania en Puerto Rico. Estado Libre Asociado de puerto Rico: Comisión de Derechos Civiles. 